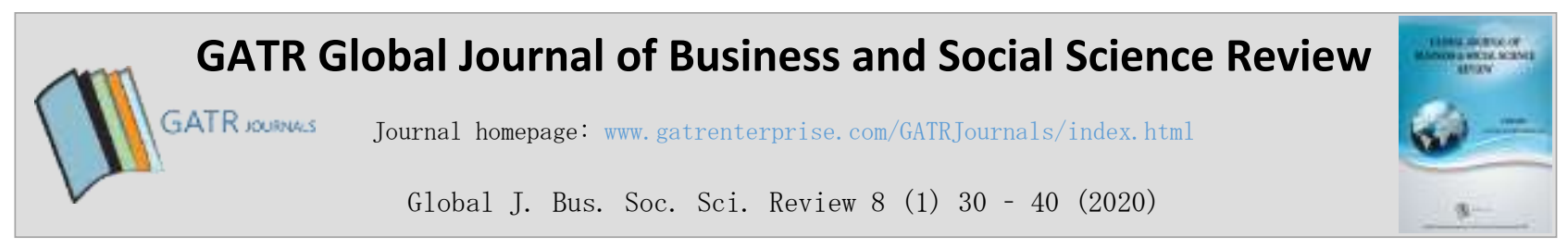

\title{
Journaling to Develop a Study Abroad Course for Business Majors
}

\author{
James G Ward ${ }^{1 *}$, Yaprak Dalat Ward ${ }^{2}$, Scott Jones ${ }^{3}$ \\ ${ }^{123}$ Fort Hays State University, 600 Park Street, Hays, Kansas, 67601, USA
}

\begin{abstract}
Objective - This research explored the cultural and educational insights in Thailand to develop a study abroad course for Business Communication students including a pre-departure segment followed by a trip to Thailand. The context was a small mid-western teaching university in the United States of America.

Methodology/Technique - The primary researcher collected textual data by means of keeping a daily journal in Thailand including visits and stays in both urban and rural areas for over a period of two months. The journaling included reflections on the primary researcher's observations and comments about learning sites, opportunities and cultural activities. The data collection also included videotaped interviews, photos of sites, local people, and cultural artifacts to be utilized in the course.

Finding \& Novelty - Content analysis of the journal yielded three sets of themes which resulted in the development of the course: a) Identification of opportunities to develop and practice intercultural sensitivity, intercultural development, and intercultural competencies; b) recognition of cultural artifacts to bring awareness to the culture of the country visited; and c) identification of a set of practical issues related to international travel.
\end{abstract}

Type of Paper: Empirical.

Keywords: Curation, experiential learning, journaling, study abroad, social enterprise, reflection.

Reference to this paper should be made as follows: Ward; J.G; Ward Y.D; Jones; S. (2020). Journaling to Develop a Study Abroad Course for Business Majors, Global J. Bus. Soc. Sci. Review, $8(1)$ : $30 \quad-\quad 40$. https://doi.org/10.35609/gjbssr.2020.8.1(4)

JEL Classification: A30, A39.

\section{Introduction}

Providing students with study abroad experiences and opportunities is a significant university service. In addition, preparing students for employability in globalized businesses is a must for today's universities. Providing students with study abroad experiences and opportunities is a significant university service. In addition, preparing students for employability in globalized businesses is a must for today's universities. The 21 st century workforce requires greater international, intercultural and global skills. In a World Economic Forum (WEF) 2015 report it was noted that "64\% of employers consider international experience as important for recruiting, reporting that graduates with an international background receive greater professional responsibility more often" (para. 4).

\footnotetext{
* Paper Info: Revised: January 15, 2020

Accepted: March 31, 2020

* Corresponding author: James G Ward

E-mail: JGWard@fhsu.edu

Affiliation: Fort Hays State University, USA
} 
Business majors must acquire these skills to compete in the real world beyond the classroom. In fact, there is ample evidence that many of the top ten 2020 key skills presented by the WEF (2018) are acquired through study abroad experiences, and include complex problem solving, critical thinking, creativity, coordinating with others, emotional intelligence, judgement and decision making, cognitive flexibility skills. In a World Economic Forum 2015 report it was noted that " $64 \%$ of employers consider international experience as important for recruiting, reporting that graduates with an international background receive greater professional responsibility more often" (para. 4).

Due to the significance of the skills required for employability based on the WEF Report (2018) the authors conducted research to develop a study abroad course for business majors at a small mid-western university in the United States of America. The purpose of developing a course was to maximize the educational opportunities for the students so that they would gain insights into the Thai culture and business and expand their competitive advantage (WEF, 2018).

This paper is organized as follows: 1) Literature Review, 2) Research Methodology, 3) Results, 4) Discussion, and 5) Conclusion.

\section{Literature Review}

The focus of this study was to utilize journaling, reflection and curation as the tools to design a study abroad course. While literature yielded ample and varied study abroad programs, and the use of journaling as part of in-country experiences, there was limited grounded research on the use of journaling to develop study abroad programs. However, there are many examples of journaling used for many reasons ranging from improving ones' professional life to personal growth. In addition, regarding research "journal writing between participants and researcher may offer the qualitative researcher yet another opportunity for triangulation of data sets at multiple levels" (Janesick, 1999, p. 504).

\subsection{Theoretical framework}

Constructivist learning theory served as the theoretical framework for this study because in study abroad experiences students observe and consider the similarities and differences between their own culture and the culture they immerse in. Novak (1998) stated that educators "must understand and engage the learner's existing relevant knowledge, both valid and invalid ideas" (p. 224). Additionally, Merriam and Caffarella (1999) noted that "learners construct their own knowledge from their experiences" and therefore construct their own "internal...reality" (p. 264- 265).

\subsection{The role of journaling and reflectivity}

Journaling and reflectivity have been used for a variety of learning experiences, one being the application of what students learn and how these learnings "affected their lives on a personal level" (Doyle, 2011, p. $101)$.

Literature yielded ample studies on nursing, particularly on nursing clinical experiences. Epp (2008) examined the use of journaling in the preparation of nurses for their nursing education and concluded that learner journaling drove reflection (p. 1379). According to a study on nurses' clinical experiences conducted by Mahlanze and Sibiya (2017), nurses "generally experienced writing of reflective journals to be a valuable tool enhancing personal development, professional growth and clinical learning" (p. 79) as part of their clinical learning.

Regarding study abroad journaling, narrative-based reflection using journals and discussions as part of a study abroad experience is critical according to Drolet (2013): "Reflective learning paves the way for crosscultural competencies in spite of the barriers and challenges confronted in diverse cultural settings" (p. 191). Cultural awareness thorough reflective journaling was also studied. Zimmerman and Musilli (2016) 
examined 27 students in a study utilizing WordPress journals. The journals were analyzed through interpretive content analysis. The researchers concluded that journals were effective teaching tools to develop student understanding, and such journals also served as powerful assessment tools throughout the semester.

Participatory involvement is critical to success of these reflective journals in which students express their own emotions and thoughts are powerful tools (Travers, 2014). However, according to Travers (2014) without guidance, the journals can become lists of foods eaten and daily schedules. Having experienced the techniques of journaling and reflectivity in Thailand, the primary researcher ensured that journaling and reflectivity become part of the course teachings as reflectivity fostered cultural awareness and development of intercultural competencies. According to Travers (2014) learners should have opportunities to interact with their peers and the local community (p. 206). In fact, students must be "prepared to maximize their learning opportunities at the foreign site, to effectively interact with locals, to develop cultural awareness, and to respond to challenging situations occurring abroad" (Goldini, 2015, p. 1).

Furthermore, with the advancement of technology, blogging as a journaling method has become increasingly popular. Bryant (2014) examined the integration of blogging into the contemplative classroom and concluded that this approach supported the 21st Century Google-aged learner.

\subsection{Study abroad as a curated experience}

Thorson and Harvey (2019) examined the pedagogical implications of short-term study abroad programs at the University of Victoria in British Columbia, Canada. The researchers focused on out there learning, the process of unlearning false concepts and examined the question "what happens when we leave campus and study in another location and in communities significantly different from out of town" (p. 5). According to the authors, study abroad "was described as curated experiences, curated by the faculty leading the trips, and faculty had a range of decisions to make including what to see, what to avoid, what to take-a-way" (p. 7). The authors also noted that the experiences could be interdisciplinary: "Attention to 'place' that comes from being 'somewhere else' often relies on an interdisciplinary approach" (p. 9), and that short term study abroad could lead to a transformational experience for learners via dialog and storytelling, hands on tasks, and reflection.

Moreover, the cultural experiences entail not only recognizing different cultures but also acquiring cultural competencies through interacting with locals and immersing in the culture. Based on the existing levels of cultural competencies, such programs should have opportunities to improve students' competency levels. One model, Intercultural Maturity Model (Spitzberg \& Chagnon, 2009), evaluates student intercultural competencies based on cognitive, interpersonal and intrapersonal skills (p. 22). The first two levels of the model are entitled the initial development and intermediate development. With this research since the university in question has students primarily with limited international travel experience, the expected transition, based on the Intercultural Maturity Model, would be to level two, intermediate development described as "willingness to interact with divergent others and explored how social system affect group norms and relations" (Spitzberg \& Chagnon, 2009, p. 22).

\subsection{Purpose and planning and international experiential learning}

Experiential learning is defined as "making meaning out of direct experiences in academic, personal, and/or professional terms" (Drolet, 2013, p. 185) as it provides a process for students "to apply and to integrate their knowledge and skills in the field while challenging their values..." (p.185).

Global Affairs Canada (2017) underlines the university supported study abroad experiences by describing major benefits to student: "Positive impact on their overall employability and career path choices...Greater intercultural competencies and higher scores of cultural intelligence .... Commitment [sic] to civic engagement and global citizenship...Intercultural skills....Direct [sic] profit from these experiences through concrete business benefits" (p. 2). 
The advantages of study abroad programs are many; however, such experiences need to be developed and designed carefully to amplify the benefits for the students and their families. As starters, addressing fundamental issues such as planning the experiences, developing learning arrangements, cultural preparation before departure, ongoing communication between faculty and students while in the field are of utmost importance (Drolet, 2013).

Another fundamental issue is the post briefing sessions as the "ends of time in the host country signals the beginning of a post-trip or post experience phase" (Travers, 2013, p. 206). In fact, many experienced program leaders would agree on the importance of the post trip event and stress the fact that "without structured time to reflect, the time abroad loses its value" (Epprecht, 2004, p. 16).

\subsection{Social enterprise in Thailand}

Business majors are often trained in a profit-based model. Current students at the university in question are concerned about the contributions of business to develop quality social values regarding sustainability to improve the natural physical environment and the effects on societal changes. Social enterprise addresses these concerns.

Srivetbodee, Kraisornsuthasinee and Igel state that (2017) "social enterprise marketing, namely product, production, price, distribution, communications and services can contribute to social value creation" (p. 1). The primary characteristics of social enterprise are "social value creation, income generation from selling goods, entrepreneurial adaptation, community and stakeholder engagement and partnership" (p. 2). Srivetbodee et al. (2017) noted that in the case of one royal agricultural site, highland fruits (strawberries, peaches, lychee) are the cash crop that replaced opium production. In addition to income generation, the royal agricultural sites "revived the land where was once full of opium and subsequent social and environmental problems, such as drugs trafficking, soil erosion and deforestation from farm shifting" (p. 11). In addition, the sites are managed in a democratic manner, and create training and development opportunities for impoverished groups (Srivetbodee, et al., 2017, pp 12-13).

\section{Research Methodology}

The primary researcher had studied with Thai students as an undergraduate, had lived in Bangkok and worked at Thai universities for several years. Before, during and after data collection, the primary researcher depended extensively on a network of colleagues and friends in Thailand for expertise. Journaling notes and reflection on these notes and comments in Thailand comprised the qualitative data. Analysis of the textual data yielded vast collection of themes which were color coded and categorized into three groups. These themes also validated the review of literature presented.

The study abroad course was developed for a teaching university located in the mid-west with an oncampus student enrollment of 4,000. Most students came from small rural agricultural communities made up a population of less than 2000. Many students were the first generation in their family to attend university. The majority of on campus students worked in order to pay rent and university expenses. A foreign language was not required as part of the general studies degree.

The university promoted the enhancement of global learning as stated in the university strategic plan: "Global engagement is critical to the advancement of the university, the state of Kansas and our nation...thus making it a moral obligation for practitioners to 'develop tools to facilitate learning and engage in dialogue to discern the complexities of our global engagement" (Fort Hays State University [FHSU], 2016, p. 1). In addition, the mission of the university Strategic Plan 2019 (FHSU, 2019) is "global in nature as the university provides accessible, quality education to Kansas, the nation, and the world...to develop engaged global citizen-leaders" (p. 4). The strategic plan also emphasizes one potential activity in the process, which is study aboard, a program that "contributes to the quality of life in a community and the economic prosperity of our region and state" (FHSU, 2019, p. 14.). The plan also validates the benefits of a study abroad program not 
only from the student point of view but also from an institutional point of view as stated by Alghamdi and Otte (2016) "financial gains on the part of the institution, the opportunity for cross cultural understanding and global awareness for host institutions and for domestic and international students" (p. 16).

Qualitative research method was the process employed to identify the cross-cultural themes for the study abroad course for Business Communication students. The primary researcher was the Thai subject matter expert and the secondary and third researchers were research specialists as well as study abroad experts. Reflective journaling data led to the development of the course description, course content, learning objectives, and learning activities. The study abroad course learning objectives were identified as 1) be able to describe the similarities, and differences, between the U.S. and Thai culture; 2) be able to analyze the role of the King in Thai culture; 3) be able to compare and contrast the concept of nation in Thailand and the U.S.; 4) be able to understand the role of Buddhism in Thai society; 5) be able to understand why Thai society is animistic; 6) be able to evaluate social enterprise regarding strengths and weaknesses?; 7) be able to evaluate the role of the elder in hill tribe culture; 8) be able to analyze learnings from interactions with Thai university interns at the Royal Agricultural Station; and 9) be able to evaluate the impact of this experience.

The course consisted of two segments: 1) A face-to-face pre-departure section. This one-credit hour course would meet a total of 16 classroom hours; 2) the in-country experience, in this case Thailand. Students would be allowed to take the in-country experience as a two-credit hour course if they wished to do so. Similar to the primary researcher's journaling and reflection activity while in Thailand, students would also be required to journal and reflect on their experiences and learnings by means of a daily blog.

Since university policy required that the study abroad experience be directly related to the content and learning objectives of an existing course, due to the students' major, the course selected for this purpose was Global Business Communication. This course was regularly taught for both Business undergraduates and graduates at the university and included the topics of intercultural sensitivity, intercultural development, and intercultural competency. At the end of the course, the students would evaluate the application of these topics to their professional and personal lives.

In addition, a detailed budget had to be presented for university approval of the study abroad course. The budget included the travel, lodging, meals and incidentals. Budget restrictions of the university already capped the experience at eight students and two faculty leaders. This ratio would allow faculty to pay attention to each students' needs, learnings and experiences. Furthermore, risk involved in study abroad programs would be minimized as required by the university. The university policies entailed a risk assessment for student international travel examining political, social, legal, environmental and health risks as part of the development of a study abroad proposal. The risk assessment also covered the U.S. State Department Travel Warnings (The U.S. Department of State-Bureau of Consular Affairs, 2019) for the U.S. citizens. When designing the course, the researchers considered the unexpected warnings and/or alerts from the source: "Outbreaks of violence between competing armed groups can occur with little warning and have the potential to impact US citizens" (The U.S. Department of State-Bureau of Consular Affairs, 2019, para 1).

The primary researcher collected qualitative data in Thailand by means of keeping a daily journal with reflections, aligned with the definition of journaling proposed by Hayman, Wilkes and Jackson (2012). Journaling is defined by Hayman, Wilkes and Jackson (2012) as "the process of participants sharing thoughts, ideas, feelings and experiences through writing and/or other media. Journaling is used in phenomenological research studies to record participant experiences in their natural contexts" (p. 27).

The daily routine involved exploring and analyzing the cultural themes. The journal aimed to capture themes which would add value to the student experience since the student experiences and learnings were fundamental in designing the course. The notes reflected such aspects of the primary researcher's observations and comments about learning sites, opportunities and cultural activities. The data collection also included videotaping interviews, and photos of sites, local people, and cultural artifacts to be shared in 
the course. In addition, journaling led the primary researcher to travel the path of students, visit the sites to be explored by the students and meet the people students would meet (Sagor, 2000).

Notes were dictated into the Notes App on an iPhone XS (2019). The technology allowed the researcher to record his observations and comments on the spot and instantaneously in a rapid manner resulting in reliable data. The videos, websites, and images captured by the researcher was uploaded to the course shell in Blackboard. The university used Blackboard as the Learning Management System (LMS) for instruction. All notes were downloaded and placed onto MS Word documents which were organized by the date they were created and by location.

The dictation into the Notes App occurred both during the day and the evening. During the day, the primary researcher took copious notes on his observations on the surroundings, made comments on his reflections on the local people who were interviewed. The researcher captured the unstructured interviews and made comments and noted his observations as part of data collection. Similar notes were added during the evening when the primary researcher discussed the day with Thai colleagues. Based on the locations, there were five categories of data sorted by location. These categories are discussed in the results section.

\section{Results}

Journaling took place in five different locations and resulted in the cultural and educational insights described below in Table 1 .

Table 1. Sites visited and cultural and educational insights.

\begin{tabular}{|l|l|}
\hline Sites visited & Cultural and educational insights \\
\hline The Museum Siam & 1. Cross cultural themes \\
\hline Monastery & 2. Religion \\
\hline Former Prime Minister's home in Bangkok & 3. Political, social, artistic history \\
\hline $\begin{array}{l}\text { Royal Agricultural Station in Angkhang in Chiang } \\
\text { Mai province and The Royal Factory in Fang }\end{array}$ & $\begin{array}{l}\text { 4. Social enterprise and cultural } \\
\text { interactions }\end{array}$ \\
\hline Hill tribe villages & $\begin{array}{l}\text { 5. Cultural interactions and } \\
\text { experience }\end{array}$ \\
\hline
\end{tabular}

The content analysis of these insights yielded three sets of themes which became the building blocks of the course description, course content, learning objectives, and learning activities. The themes included: a) Identification of opportunities to develop and practice intercultural sensitivity, intercultural development, and intercultural competencies; b) recognition of cultural artifacts to bring awareness to the culture of the country visited; and c) identification of a set of practical issues related to international travel.

\subsection{Identification of opportunities to develop and practice intercultural sensitivity, intercultural development, and intercultural competencies}

The primary researcher's visit to the first cultural site, the Museum Siam, was the catalyst for the specific organization of the cross-cultural themes. The museum had 14 rooms dedicated to a major theme: Decoding Thainess which was the name of the permanent interactive exhibition. Three cultural themes were covered at the exhibition: The King, The Nation and Buddhism. The three themes of Decoding Thainess were presented via artifacts and interactive displays.

Reflecting on the exhibits in the Museum Siam, the primary researcher and a Thai colleague compiled a list of physical sights to be visited which would add to the students' cultural experience. Two other museums

Global J. Bus. Soc. Sci. Review 8 (1) $30-40$ (2020) 
and temples were also selected for the same reason. In addition, journaling led to reflection on the artifacts which were collected, photos which were taken and videos which were made to be utilized in the predeparture course. The primary researcher's assumption was that he, too, had to have similar experiences in order to realize potential student reactions as suggested by Sagor (2000).

When visiting the first site, the Museum Siam, the primary researcher realized that the King himself represented both the nation (the military) and Buddhism. Reflection then led to the question: What books, articles, events and artifacts reflect the profound role of the King? The following materials and names of sites were identified to represent the King: the royal palace and selected temples and photos of the King as displayed in Thailand-in individual homes, in restaurants, on skyscrapers and in airports, secondary schools and universities and government buildings.

The role of the King and the nation led to reflection on how to express this concept. Due to the primary researcher's network of friends and colleagues, a Thai Colonel in the Royal Thai Immigration Police agreed to meet the students and discuss this concept of the nation from the immigration police perspective. This topic was particularly important as immigration has been a global issue. It was fundamental for students understanding of global issues how immigration affects many countries and businesses.

The researcher also visited a former Prime Minister's home who was a member of the Royal Family, an accomplished newspaper writer and a novelist as well as an accomplished artist of Khon, a masked drama dance. The primary researcher purchased a set of Khon masks, books, and located an essay entitled What is Thainess? written by the Prime Minister. These cultural items were all incorporated into the course so that students could gain an insight into the country's political, social and artistic history.

Regarding the concept of Buddhism, the religion of the country, to gain a better understanding of the religion, the primary researcher engaged in different activities he participated in: 1) conducting a conversation with a monk; 2) feeding the monks in the morning; 3) participating in the blessing of Buddha images at a small rural monastery. These three events occurred in three different cities. The primary researcher met with a monk for one hour and discussed the open-ended question- What is the one major idea you would want U.S. students to take away? The event was photographed, and notes were taken by a Thai colleague. Later, as the primary researcher traveled around the country, he fed monks in the morning, a daily event in Thailand. Thirdly, the primary researcher attended a Buddhist ceremony to bless two Buddha images. The event was also photographed and videotaped. In addition, an American colleague was videotaped discussing his three months in the monkhood, the meaning of Buddhism and about acceptable and unacceptable cultural behaviors in Thailand.

During discussions and readings while in Thailand, the primary researcher learned that the previous King, His Majesty King Bhumibol Adulyadej, founded a series of social enterprise agricultural sites in the northern Thai mountains, to teach hill tribe villagers to grow crops to end opium production. This led to an additional visit as it was related to social enterprise. The primary researcher also learned that these stations were nonprofit businesses. They were social enterprises, created to enhance the lives of citizens. The primary researcher then travelled to the Royal Agricultural Station in Angkhang in Chiang Mai province. The meeting was arranged by one of the principle researcher's Thai colleagues. The site represented the King and his desire to promote the lives of those in the Kingdom. In addition, the primary researcher interviewed the manager of the site at the Royal Factory in Fang, a site that provides experiential learning about the relationship of the factory to the town and agricultural site through exhibits, artifacts, and films. This, in turn, led to journaling concerning possible student experiences at the Royal Factory.

After listing potential student activities, the following experiential activities were selected for a five-day stay at the Royal Agricultural Station in Angkhang in Chiang Mai province. Students would be briefed on each area of production: fruits, mushrooms, wood production, and then work with the hill tribes in this production process. They would also visit two villages of different hill tribes. A mountain hike was added to view tea production. Another trip was added to the town of Fang and the Royal Factory to observe the 
canning, packaging and shipping process. Students would also visit a store selling all the products produced at the agricultural station. These visits would expose students to the entire supply chain process, a common business instructional practice. In addition, potential activities between the U.S. students and Thai university interns at the site were journaled and then discussed with the staff of the Royal Agricultural Station. This opportunity would provide both Thai and American students with "cognitive, interpersonal and intrapersonal" cross cultural experiences based on the Intercultural Maturity Model (Spitzberg \& Chagnon, 2009, p. 22) previously discussed.

Moreover, following a visit to the Royal Agricultural Station site, the principle researcher visited the two hill tribe villages which students would visit and immerse in cultural interactions. The primary researcher visited five other hill tribe villages to gain more insight into hill tribe culture. These visits included: 1) meeting a local shaman in his environment to observe a ceremony focused on communication with the spirits of the dead; 2) a village to observe and make steel knives used in village life; 3 ) a village visit to make long bows and bows and arrows used in hunting; and finally, 4) another village which produced rice wine. Observing how local people produced wine would be important for the students to gain an agricultural point of view of wine production and marketing.

\subsection{Recognition of cultural artifacts to bring awareness to the culture of the country visited}

Based on the visits described above, cultural artifacts with photos were also collected. Some of the artifacts included Thai spirit houses as well as the images commonly found in the spirit houses. Two shops specializing in Buddhism were visited and monk robes were collected. Hill tribe cultural artifacts were also gathered as instructional materials. Offerings given to monks, candles for worship, amulets worn around the neck were collected. These artifacts would provide students with insights into the Thai culture.

\subsection{Identification of a set of practical issues related to international travel}

Preparation of students for international travel (from passports and photos to boarding the aircraft and arrival in Bangkok) and identification of restaurants (Thai and western) were examples of themes which appeared as a result of journaling. To assist students' understanding of international airports, photos were taken at the airports and departure gates. Artifacts were collected- airline travel magazines, lists of movies on board, airline menus, the airline tickets and baggage claim forms. In addition, a journal entry indicated students must know in advance the luggage and weight limitation and ways to quickly identify their own luggage. Photos were taken of the Bangkok airport exit for the U.S. passport holders, as well as the zone where students would be met upon arrival by the hotel van. All the photos were converted to video via Screencast-o matic (2019), a screen recording and video editing online system, and uploaded to the course site.

A journal was kept concerning Thai meals and restaurants and Thai eating etiquette. As a result, the primary researcher took photos of menus, indicating the food and price, and a journal entry was created listing all the differences between Thai and American dining rules. The journal identified significant differences between Thai and American eating customs. This observation led to the decision that the Thai guide accompanying the students and faculty would conduct an etiquette dinner.

One key issue identified by (Drolet, 2013) which was ongoing communication between faculty and students while in the field, was settled. A question was postulated in the journal: How can students and faculty communicate, when students are out in the evening or on their free day or afternoon? The journal listed two solutions to explore: a SIM card and buying a local phone and service. The principle researcher went to a phone service and discovered that SIM cards could not be removed from an iPhone (most students used iPhones) and local phones were too expensive. When the primary researcher inquired about Wifi at the Royal Agricultural Station, he learned of the existence of portable Wifi units that can be carried in one's 
pocket, an uncommon device in the U.S. Ten individuals can link to the device and, therefore, students management since knowing where the students were mitigates the risk of students getting lost during the trip.

\section{Discussion}

The journaling and reflection were both based on the previous grounded research reported in the review of literature. Through the lenses of the previous findings, the trip was treated as an exploratory opportunity (Bogdan \& Biklen, 2003) to design a study abroad course because the nature of the trip was different than the primary researcher's previous trips to Thailand.

Once the trip ended, the primary researcher reviewed the textual data to analyze the words and images. The documents were rich in data. Once the analyses were completed, the three researchers met to discuss their findings. Upon agreeing on the themes, the process of designing the course began. The data were analyzed by the three researchers independently to maintain the reliability of the findings. All three researchers were experienced in study abroad trips and had ample expertise in color-coding which led to identify themes. The primary researcher was the Thai subject matter expert and the secondary and third researchers were research specialists and study abroad experts as well.

Cultural themes were identified which would help students decipher the culture of the country and bring awareness as part of a study abroad course. The content analysis of the journals yielded three sets of themes: a) identification of opportunities to develop and practice intercultural sensitivity, intercultural development, and intercultural competencies; b) identification of cultural artifacts to bring awareness to the culture and c) identification of a set of practical issues to be addressed in the pre-departure course. These themes became the building blocks of the course description, course content, learning objectives, and learning activities.

According to the themes, the course description was identified as follows. This course will enable students to develop and practice intercultural sensitivity, intercultural development, and intercultural competencies; recognize cultural artifacts to bring awareness to the culture of the country visited; and identify a set of practical issues related to international mobility.

In addition, the following course learning objectives were identified as 1) be able to describe the similarities, and differences, between the U.S. and Thai culture; 2) be able to analyze the role of the King in Thai culture; 3) be able to compare and contrast the concept of nation in Thailand and the U.S.; 4) be able to understand the role of Buddhism in Thai society; 5) be able to understand why Thai society is animistic; 6) be able to evaluate social enterprise regarding strengths and weaknesses?; 7) be able to evaluate the role of the elder in hill tribe culture; 8) be able to analyze learnings from interactions with Thai university interns at the Royal Agricultural Station; and 9) be able to evaluate the impact of this experience.

Finally, the learning activities were developed and were based on the Intercultural Maturity Model (Spitzberg \& Chagnon, 2009, p. 22) since the findings validated the model which identifies three levels of competencies: Initial, intermediate and mature development levels. The learning activities ranged from discussions to blogging reflective journals, role play, debates and dialogs, collaborative research and would lead students to apply, analyze and evaluate their experiences and insights into their personal and professional lives.

\section{Conclusion}

The purpose of this research was to explore the cultural and educational insights in Thailand as part of a study abroad course at a small mid-western university in the U.S. The research guided the creation of the study abroad course with a segment on pre-departure and in-country trip.

The implications of developing a study abroad course based on fieldwork proved to be fundamental. Walking in the same path of the students allowed a deeper understanding of potential student experiences. In addition, having a strong network of friends and colleagues in the country, and possessing country knowledge through social interactions with the people of that country, proved to be an extremely valuable 
advantage. Furthermore, designing a study abroad experience based on grounded research confirmed a more beneficial experience.

Future research is recommended regarding student learning and attitudinal changes upon completion of the trip utilizing the Intercultural Maturity Model (Sptizberg \& Changnon, 2009). The research would focus on 1) the impact of the study abroad program on the Royal Agricultural Station in Angkhang; 2) the effectiveness of post-reflection upon completion of a study abroad trip versus pre-departure reflection; and 3) the impact physical cultural artifacts on the promotion of learner insights.

\section{References}

Alghamdi, H. \& Otte, S. (2016). The challenges and benefits of study abroad. International Journal of Humanities and Social Sciences, 6(5), 16-23.

Bogdan, R. C., \& Biklen, S. K. (2003). Qualitative research for education: An introduction to theories and methods (4th ed.). Boston, MA: Pearson Education Group, Inc.

Bryant, K. N. (2014). Composing online: Integrating blogging into a contemplative classroom. In

K.E. Pytask \& R. E. Fertig (Eds.), Exploring technology for writing and writing instruction (pp. 77-99). Hershey, PA: Information Science Global (IGI)

Doyle, T. (2011). Learner-centered teaching: Putting the research of learning into practice. Sterling, VA: Stylus Publishing, Inc.

Drolet, J. (2013). Getting prepared for international experiential learning. In R. Tiessen \&

Tiessen, R., \& Huish, R. (Eds.). (2014). Globetrotting or global citizenship?: Perils and potential of international experiential learning. University of Toronto Press. (pp 185-187).

Epp, S. (2008). The value of reflective journaling in undergraduate nursing education: A literature review. International Journal of Nursing Studies, 45(9), 1379-1388. https://doi.org/10.1016/j.ijnurstu.2008.01.006

Epprecht, M. (2004). Work- study abroad courses in international development studies: Some ethical and pedagogical issues. Canadian Journal of Development Studies, 25(4), 26-36. https://doi.org/10.1080/02255189.2004.9669009

Fort Hays State University. (2016). A Duty to Dream: The Development of a Creative University A Strategic Map of Fort Hays State University in 2020, Hays, Kansas: Author.

Fort Hays State University. (2019). Unlocking Untapped Potential: Strategic Plan 2019, Retrieved from https://fhsu.edu/president/strategic-plan/untapped-potential/index

Global Affairs Canada. (2017, March). Outbound Mobility of Young Canadians: Benefits, Challenges and Recommendations, Canada: Author.

Goldini, F. (2015). Preparing students for study abroad. Journal of the Scholarship of Teaching and Learning, 15(4), 120.

Hayman, B., Wilkes, L. \& Jackson, D. (2012). Journaling: Identification of challenges and reflection strategies. Nurse Res. 19(3). 27-31. https://doi.org/10.7748/nr2012.04.19.3.27.c9056

iPhone XS Notes App. (2019). Use Notes on your iPhone, iPad, and iPod touch. Retrieved from https://support.apple.com/en-us/HT205773

Janesick, V. J. (1999). A journal about journal writing as a qualitative research technique: History, issues, and reflections. Qualitative Inquiry, 5, 504-521. https://doi.org/10.1177/107780049900500404

Mahlanze, H. T., \& Sibiya, M. N. (2017). Perceptions of student nurses on the writing of reflective journals as a means for personal, professional and clinical learning development. Health SA Gesondheid, 22(1), 79-86. http://dx.doi.org/10.4102/hsag.v22i0.971

Sagor, R. (2000). Guiding School Improvement with Action Research. Alexandria, Virginia: Association for Supervision and Curriculum Development.

Screencast-o matic (2019). Retrieved from https://screencast-o-matic.com/

Sptizberg, B. H., \& Changnon, G. (2009). Conceptualizing intercultural competence. In D. K. Deardorff (Ed.), The Sage Handbook of Intercultural Competence (pp. 2-52). Thousand Oaks, CA: SAGE Publication, Inc.

Srivetbodee, S., Igel, B., \& Kraisornsuthasinee, S. (2017). Creating social value through social enterprise marketing: case studies from Thailand's food-focused social entrepreneurs. Journal of Social Entrepreneurship, 8(2), 201-224. https://doi.org/10.1080/19420676.2017.1371630

Thorson H., \& Harvey, M. (2019). Out there learning: Critical reflections on off-campus study programs. Toronto, Canada: University of Toronto Press. 
Travers, S. (2014). Getting the most out of studying abroad: Ways to maximize learning in short-term study trips. In R. Tiessen \& R. Huish (Eds.), Global trotting or global citizenship? Perils and potential of international experiential learning (pp 198-209). Toronto, Canada: University of Toronto Press.

U.S. Department of State-Bureau of Consular Affairs. (2019). Travel Advisories. Retrieved from https://travel.state.gov/content/travel/en/traveladvisories/traveladvisories.html/

World Economic Forum (2015). Why studying abroad could help you get hired. World Economic Forum. Retrieved from https://www.weforum.org/agenda/2015/11/study-abroad-get-hired/

World Economic Forum (2018). The future of jobs report 2018. World Economic Forum. Retrieved from http://www3.weforum.org/docs/WEF_Future_of_Jobs_2018.pdf

Zimmerman, S. J., Olin, J., \& Musilli, S. (2016, April). AERA Online Paper Repository, Paper presented at the Annual Meeting of the American Educational Research Association, Washington, DC. 